VEETHIKA- An International Interdisciplinary Research Journal

E-ISSN: 2454-342x

Double Blind Peer Reviewed Journal

URL: http://veethika.qtanalytics.in

\title{
Measurement and improvement of efficiency of Library by mathematical modelling and finding reliability
}

\author{
Yakshi Bahl' ${ }^{1}$ Tarun Kumar Garg ${ }^{2}$ \\ ${ }^{1,2}$ Department of Mathematics, Satyawati College, University of Delhi, Delhi \\ Email: ${ }^{1}$ yakshi.anand@gmail.com, ${ }^{2}$ tkgarg@ satyawati.du.ac.in
}

\begin{abstract}
Here in this paper, we have developed the mathematical model of the library server using Markov birth - death process assuming that library system server system is based on exponential distribution. The model so developed by victimisation Chapman Kolmogorov differential equation and is solved by using Mathematica. The solution so obtained is analysed for various rates of failures and repair. The finding so obtained are discussed with the concerned authorities of the library to boost the efficiency of the library.
\end{abstract}

\section{KEY WORDS}

Chapman Kolmogorov Differential Equation, Library Client Server, Library Mirror Server, Markov Process, Mathematica, Reliability

\section{INTRODUCTION}

In today's era we all witness a long boom in Information technology that has transformed the world astonishingly into a better place. Of course, not to forget the risks those are brought along. These risks have pushed us to go after the diagnostic approach and minimize the risks, keeping the output optimised. And this is what showed us the way to go for investigating and improving the reliability of the system. Reliability is a well chosenword for measuring the efficiency of a system at a given time $t$. In the field of education, Library is the prime intellect reservoir of any academic Institute however small or large. Library servers have now-a-days been upgraded from just catalogue holders to a digital epitome of knowledge. So, their undisrupted functioning has became a subject of extreme importance. In this paper, we measure the efficiency of library by surveying and identifying the methodology or set-up so as to boost the reliability of the server system. A server yields the assistance in optimising the client's request, centralising the storage of data and securing the retained data. Redundancy dole out important role to maintain the backup in case of any data breaches. This system is composed of client server and mirror server. In the event of any glitches in client-server, the system is taken over by mirror-server, resulting in ceaseless operation or functioning. However, client-server takes back its position, once fixed.

\section{LITERATURE REVIEW}

The given literatures discussed the various ways to analysed reliability. In [2] Arora et al. have performed the "System Analysis and maintenance management of the coal handling system in a paper plant". In [3] Kumar et al. have run the "Reliability analysis of the Feeding System in the Paper Industry". In [5] Kumar et al. have done "Performance evaluation and availability Analysis of ammonia synthesis unit in a fertilizer plant". In [6] Khanduja et al. discussed the "Availability analysis of bleaching system of a paper plant". In [8] Kumar et al. have analysed the "Performance Modelling and Simulated Availability of Shell Gasification and Carbon Recovery Unit of Urea Plant". In [10] Jindal et al. performed the "Analysis of the reliability of the Butteroil Prrocessing plant using CAS Mathematica and Maxima". In [12] Lindemann et al. have used "Numerical methods for reliability evaluation of markov closed fault-tolerant systems". In [13] Modgil et al. gave study about "Performance modelling and availability analysis of shoe upper manufacturing unit". In [16] Garg et al. have analysed the Mathematical modelling and performance analysis of combed yarn production system. In [17] Shakuntla et al. have performed Reliability analysis of polytube industry using supplementary variable technique. 


\section{SERVER SYSTEM}

\section{System description}

The system under study comprises of client server unit 'CS' and mirror server unit 'MS'. Standby state comes into action when either CS or MS do not execute the designated commands. And the working of the system ceases once either of the component server stops working completely or both of them simultaneously unable to execute the designated commands.

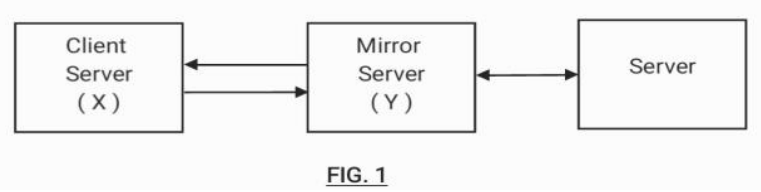

Notations and Assumptions

Notations:

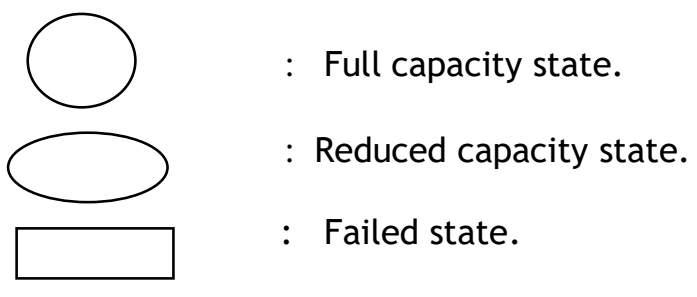

- $\mathrm{X}, \mathrm{Y}$ : denotes that unit CS and MS are in full capacity state respectively.

- $\mathrm{X}_{\mathrm{s}}, \mathrm{Y}_{\mathrm{s}}$ : denotes that unit CS and MS are in reduced capacity state respectively.

- $\mathrm{x}, \mathrm{y}$ : denotes that unit CS and MS are in failed state respectively.

- $\mathrm{x}_{1}, \mathrm{x}_{2}$ : mean failure rates of CS and MS respectively, from full working state to reduced state.

- $\mathrm{x}_{3}, \mathrm{x}_{4}$ : mean failure rates of CS and MS respectively, from reduced state to failed state.

- $\mathrm{y}_{1}, \mathrm{y}_{2}$ : mean repair rates of CS and MS respectively, from reduced state to full working state.

- $\mathrm{y}_{3}, \mathrm{y}_{4}$ : mean repair rates of CS and MS respectively, from failed state to full working state.

- $P_{i}(t)(i=1,2,3,4,5)$ : probability that the system is in specific " $\mathrm{j}^{\text {th }}$ " state at any time $\mathrm{t}$.

- $P_{i}^{\prime}(\mathrm{t})(i=1,2,3,4,5)$ : derivative with respect to $\mathrm{t}$.

\section{Assumptions:}

$>$ Mean failure and repair rates are independent and constant throughout.

System remain ceaseless in reduced state.

$>$ Server units cannot have a simultaneous failure.

$>$ Each server unit has its own repairing facility.

$>$ After repairing, the server units are as good as new in performance.

$>$ Failure and repair follow exponential distribution.
MATHEMATICAL MODELING OF THE SYSTEM

We can see the involved viable states corresponding to the mathematical model of Library Server System, in the Transition diagram (FIG 2) given below.

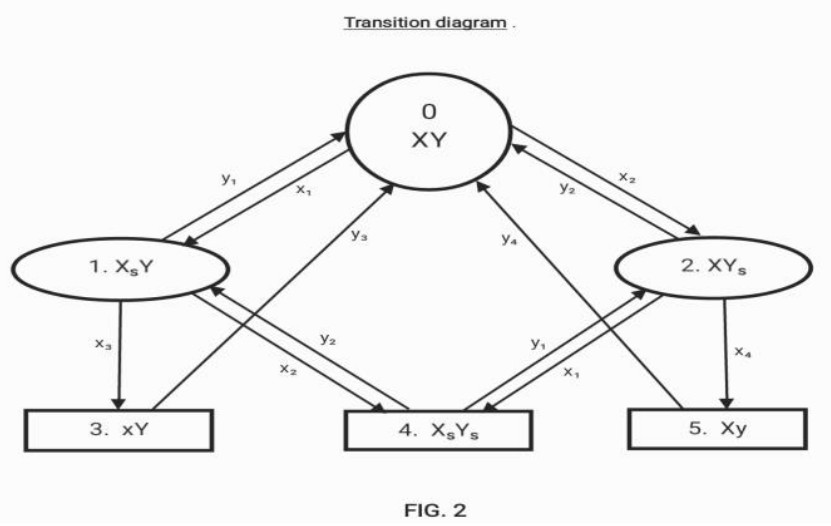

\section{Transient state}

The accompanying system of differential equations with initial condition for each state can be written as follows:

$$
\left[\frac{d}{d t}+x_{1}+x_{2}\right] P_{0}(t)=y_{1} P_{1}(t)+y_{2} P_{2}(t)+y_{3} P_{3}(t)+y_{4} P_{4}(t)
$$

$$
\begin{aligned}
& {\left[\frac{d}{d t}+x_{2}+x_{3}+y_{1}\right] P_{1}(t)=x_{1} P_{0}(t)+y_{2} P_{4}(t) \ldots} \\
& {\left[\frac{d}{d t}+x_{1}+x_{4}+y_{2}\right] P_{2}(t)} \\
& =x_{2} P_{0}(t)+x_{4} P_{5}(t)+x_{1} P_{4}(t) \\
& {\left[\frac{d}{d t}+y_{3}\right] P_{3}(t)=x_{3} P_{1}(t)} \\
& {\left[\frac{d}{d t}+y_{1}+y_{2}\right] P_{4}(t)=x_{2} P_{1}(t)+x_{1} P_{2}(t)} \\
& {\left[\frac{d}{d t}+y_{4}\right] P_{5}(t)=x_{4} P_{2}(t)}
\end{aligned}
$$

With initial conditions at time $\mathrm{t}=0$

$\mathrm{P}_{\mathrm{i}}(\mathrm{t})=$

$\left\{\begin{array}{l}1 \text { for } i=0 \\ 0 \text { for } i \neq 0\end{array}\right.$

Using Computer Algebra System Mathematica, the above of equations are solved under real working conditions at time $t$. Hence the reliability $R(t)$ of the system is given as:

$\mathrm{R}(\mathrm{t})=\mathrm{P} 0(\mathrm{t})+\mathrm{P} 1(\mathrm{t})+\mathrm{P} 2(\mathrm{t})$

Where,

$\mathrm{P}_{0}(\mathrm{t})$ gives the probability of full working state 0 .

$P_{1}(t)$ gives the probability of reduced working state 1.

$P_{2}(t)$ gives the probability of reduced working state 2 . 
After solving resulting model, the values of working states $P_{0}, P_{1}, P_{2} P_{3} P_{4}$ and $P_{5}$ at a time $t$, are obtained as follows:

$P_{0}(\mathrm{t})=-$

$\left[0.023990370644286076 e^{-0.54 t}\left(1 . e^{0.34976830452243385 t}+\right.\right.$ $3.40726716122701 e^{0.3951342549980241 t}+$ $1.909099038740512 e^{0.44181651301855174 t}+$ $4.661287752030304 e^{0.48513133987897306 t}+$ $0.5414930236131562 e^{0.4913699666887976 t}+$ $\left.\left.30.164244032696587 e^{0.5367796208932196 t}\right)\right]$

$P_{1}(t)=$

$\left[-0.05528845555008991 e^{-0.54 t}\left(1 . e^{0.34976830452243385 t}-\right.\right.$ $1.1561337172449813 e^{0.3951342549980241 t}+$ $1.9075651061495396 e^{0.44181651301855174 t}$ $0.4252196961002806 e^{0.48513133987897306 t}-$ $0.034512325273643195 e^{0.4913699666887976 t}-$ $\left.\left.1.2916993675306339 e^{0.5367796208932196 t}\right)\right]$

\section{$P_{2}(t)$}

$=\left[-0.013747625908532735 e^{-0.54 t}\left(1 . e^{0.34976830452243385 t}\right.\right.$

$+9.959337477120462 e^{0.3951342549980241 t}$

$-0.969383277446213 e^{0.44181651301855174 t}$

$-1.064267593411189 e^{0.48513133987897306 t}$

$+0.09060990759756882 e^{0.4913699666887976 t}$

$\left.\left.-9.01629651386063 e^{0.5367796208932196 t}\right)\right]$

$P_{3}(t)=\left[0.003942650437321059 e^{-0.54 t}\left(1 . e^{0.34976830452243385 t}\right.\right.$ $-1.7090108907558617 e^{0.3951342549980241 t}$ $+5.55171710947751 e^{0.44181651301855174 t}$ $-12.247574784912405 e^{0.48513133987897306 t}$ $+3.532729611290014 e^{0.4913699666887976 t}$ $\left.\left.+3.872138954900745 e^{0.5367796208932196 t}\right)\right]$

$P_{4}(t)=\left[0.03090213711675108 e^{-0.54 t}\left(1 . e^{0.34976830452243385 t}\right.\right.$ $-0.5720144970575687 e^{0.3951342549980241 t}$ $-1.234079939922848 e^{0.44181651301855174 t}$ $+0.2097130290694348 e^{0.48513133987897306 t}$ $+0.008206082427793587 e^{0.4913699666887976 t}$ $\left.\left.+0.5881753254831884 e^{0.5367796208932196 t}\right)\right]$

$P_{5}(t)=\left[0.0019607016604505207 e^{-0.54 t}\left(1 . e^{0.34976830452243385 t}\right.\right.$ $+14.722013517321502 e^{0.3951342549980241 t}$ $-2.8212624091780967 e^{0.44181651301855174 t}$ $-30.65402910778671 e^{0.48513133987897306 t}$ $-9.274956152857118 e^{0.4913699666887976 t}$ $\left.\left.+27.028234152500417 e^{0.5367796208932196 t}\right)\right]$

\section{Analysis of the Reliability of the system}

We calculate the reliability of the system by victimisation Eq. (7), and analysed the impact of variation in failure and repair rates on reliability of the system. Tables 1, 2 and 3 briefly explain the variation in reliability with graphical plotting.
In Table-1 (Effect of failure and repair rates of subsystem on the reliability of the system) the reliability of the system is computed by varying their values as $\mathrm{x}_{1}=\mathrm{x}_{3}=0.01,0.02,0.03$ and remaining constants fixed as: $x_{2}=0.02 ; x_{4}=0.02 ; y_{1}=0.05 ; y_{2}=0.1 ; y_{3}=$ $0.05 ; y_{4}=0.05$; . we observe that the reliability of the system decreases with increase in failure rate and also with passage of time.

\begin{tabular}{|c|c|c|c|}
\hline $\begin{array}{l}\mathrm{R}(\mathrm{t}) \\
\mathrm{t}\end{array} \rightarrow$ & $x_{1}=x_{3}=0.01$ & $x_{1}=x_{3}=0.02$ & $x_{1}=x_{3}=0.03$ \\
\hline 0 & 1 & 1 & 1 \\
\hline 5 & 0.987507 & 0.977492 & 0.96653 \\
\hline 10 & 0.9629 & 0.934739 & 0.90576 \\
\hline 15 & 0.935888 & 0.889314 & 0.844161 \\
\hline 20 & 0.909883 & 0.846704 & 0.788843 \\
\hline 25 & 0.885886 & 0.808184 & 0.740763 \\
\hline 30 & 0.864003 & 0.773638 & 0.699117 \\
\hline 35 & 0.844031 & 0.742554 & 0.662759 \\
\hline 40 & 0.825692 & 0.714365 & 0.630627 \\
\hline 45 & 0.808711 & 0.688566 & 0.601852 \\
\hline 50 & 0.792851 & 0.664732 & 0.575748 \\
\hline 55 & 0.777912 & 0.642524 & 0.551791 \\
\hline 60 & 0.763733 & 0.621671 & 0.529583 \\
\hline
\end{tabular}

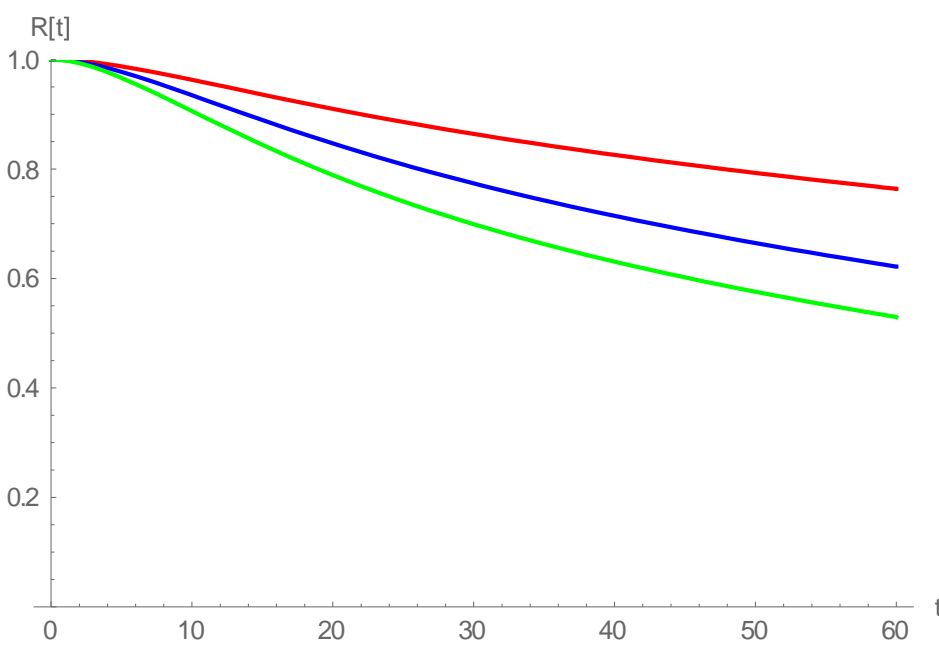

Note: 'Red' for $\mathrm{x}_{1}=\mathrm{x} 2=0.01$, 'Blue' for $\mathrm{x} 1=\mathrm{x} 2=0.02$, 'Green' for $x 1=x 3=0.03$

When $\mathrm{y}_{1}=\mathrm{y}_{2}=0.060$

Graph 1

In Table-2 (Effect of failure and repair rates of subsystem on the reliability of the system) the reliability of the system is computed by varying their values as $\mathrm{x}_{1}=\mathrm{x}_{3}=0.01,0.02,0.03$ and remaining constants fixed as: $x_{2}=0.02 ; x_{4}=0.02 ; y_{1}=0.06 ; y_{2}=0.1 ; y_{3}=$ $0.06 ; y_{4}=0.05$; . we observe that the reliability of the system decreases with increase in failure rate and also with passage of time.

At same time if we analyse Table -1 and Table -2 , we observe that reliability of the system increases with increase in repair rate. 


\begin{tabular}{|l|l|l|l|}
\hline$R(\mathrm{t}) \rightarrow$ & $x_{1}=x_{3}=0.01$ & $x_{1}=x_{3}=0.02$ & $x_{1}=x_{3}=0.03$ \\
\hline 0 & 1 & & \\
\hline 5 & 0.988491 & 0.979424 & 0.969374 \\
\hline 10 & 0.966069 & 0.940831 & 0.914542 \\
\hline 15 & 0.941752 & 0.90034 & 0.859709 \\
\hline 20 & 0.918623 & 0.862761 & 0.810983 \\
\hline 25 & 0.897523 & 0.829065 & 0.768918 \\
\hline 30 & 0.87848 & 0.799005 & 0.732575 \\
\hline 35 & 0.861253 & 0.772021 & 0.700799 \\
\hline 40 & 0.845546 & 0.747544 & 0.672577 \\
\hline 45 & 0.831081 & 0.725085 & 0.64711 \\
\hline 50 & 0.817618 & 0.70425 & 0.62379 \\
\hline 55 & 0.804964 & 0.684731 & 0.602166 \\
\hline 60 & 0.792963 & 0.66629 & 0.581908 \\
\hline
\end{tabular}

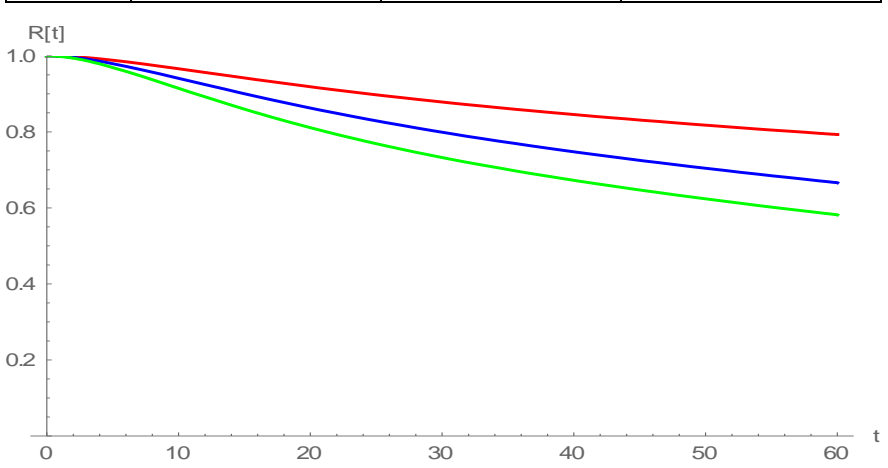

Note: 'Red' for $\mathrm{x}_{1}=\mathrm{x} 2=0.01$, 'Blue' for $\mathrm{x} 1=\mathrm{x} 2=0.02$, 'Green' for $\mathrm{x} 1=\mathrm{x} 3=0.03$

Graph 2

\section{When $\mathrm{y}_{1}=\mathrm{y}_{2}=0.070$}

In Table-3 (Effect of failure and repair rates of subsystem on the reliability of the system) the reliability of the system is computed by varying their values as $\mathrm{a}_{1}=\mathrm{a}_{3}=0.01,0.02,0.03$ and remaining constants fixed as: $x_{2}=0.02 ; x_{4}=0.02 ; y_{1}=0.07 ; y_{2}=0.1 ; y_{3}=$ $0.07 ; y_{4}=0.05$; . we observe that the reliability of the system decreases with increase in failure rate and also with passage of time.

If we analyse Table -1 , Table -2 and Table -3 altogether, we observe that reliability of the system increases with increase in repair rate, decreases with increase in failure rate and also decreases with passage of time.

\begin{tabular}{|l|l|l|l|}
\hline $\begin{array}{l}\mathrm{R}(\mathrm{t}) \rightarrow \\
\mathrm{t}\end{array}$ & $x_{1}=x_{3}=0.01$ & $x_{1}=x_{3}=0.02$ & $x_{1}=x_{3}=0.03$ \\
\hline 0 & 1 & 1 & 1 \\
\hline 5 & 0.989475 & 0.981356 & 0.972218 \\
\hline 10 & 0.969237 & 0.946924 & 0.923329 \\
\hline 15 & 0.947617 & 0.911374 & 0.875278 \\
\hline 20 & 0.927366 & 0.878846 & 0.833189 \\
\hline 25 & 0.909168 & 0.850011 & 0.797223 \\
\hline 30 & 0.892976 & 0.824501 & 0.766323 \\
\hline 35 & 0.878513 & 0.801718 & 0.739335 \\
\hline 40 & 0.865471 & 0.781095 & 0.715302 \\
\hline 45 & 0.853566 & 0.762166 & 0.693494 \\
\hline 50 & 0.842564 & 0.744566 & 0.673379 \\
\hline 55 & 0.832276 & 0.728018 & 0.654574 \\
\hline 60 & 0.822554 & 0.712314 & 0.636806 \\
\hline
\end{tabular}

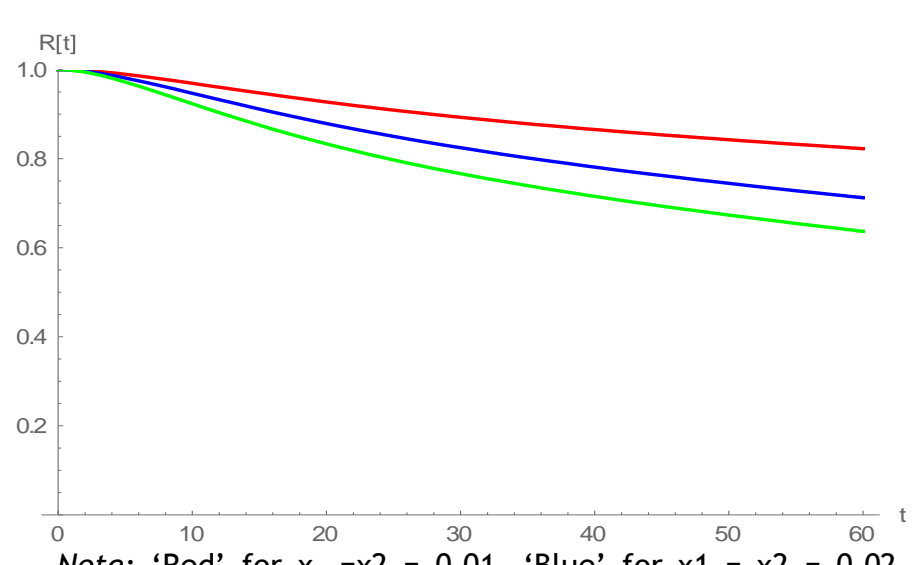

Note: 'Red' for $\mathrm{x}_{1}=\mathrm{x} 2=0.01$, 'Blue' for $\mathrm{x} 1=\mathrm{x} 2=0.02$, 'Green' for $x 1=x 3=0.03$

$$
\text { Graph }-3
$$

\section{DISCUSSION AND CONCLUSION}

The analysis of library server can help in finding the reliability of client and mirror server by using CAS Mathematica. The variation of reliability with change in failure rates $\left(x_{i}\right)$ and repair rates $\left(y_{i}\right)$ of unit $A$ and unit $B$ are shown above by Table-1, Table-2 \& Table-3. We observed that reliability of the system increase with increase in repair rate and vice versa for transient states. The findings of the paper will be useful for library workers, working on server. Mathematica is method for better accuracy. Values given by Mathematica are exact values not approximates. Also, Mathematica gives individual values of $\mathrm{P}_{0}, \mathrm{P}_{1}, \mathrm{P}_{2}, \mathrm{P}_{3}, \mathrm{P}_{4}$ even for complex structures at point $t$ which is not possible to determine by other methods for complex models. $\mathrm{P}_{0}, \mathrm{P}_{1}, \mathrm{P}_{2}, \mathrm{P}_{3}, \mathrm{P}_{4}$ are continuous function of time so $R(t)$ is also continuous function of time, not discrete so by victimisation this method, we can solve system for transient state also not only for steady state. This software not only gives accuracy in results but also save computation time.

\section{REFERENCES}

[1] Arora, N. and Kumar, D. (1997), “Availability analysis of steam power generation system in thermal power plant", Microelectron Reliability, Vol. 37 No. 5, pp. 795-799.

[2] Arora, N. and Kumar, D. (2000), "System Analysis and maintenance management or the coal handling system in a paper plant", International Journal management and Systems, Vol. 16, No. 2, pp. 137-156.

[3] Kumar, D., Singh, I. P. and Singh, J., 1988, Reliability analysis of the Feeding System in the Paper Industry. Microelectron Reliability, 28(2), 213-215.

[4] Kumar, D., Pandey, P. C., 1993, Maintenance planning and resource allocation in urea fertilizer plant. International Journal of Quality and Reliability Engineering, 9, 411-423.

[5] Kumar, S., Tewari, P. C. and Kumar, S., 2009, Performance evaluation and availability Analysis of ammonia synthesis unit in a fertilizer plant. Journal of Industrial Engineering International,5(9) 17-26. 
[6] Khanduja, R., Tewari, P. C. and Kumar, D., 2008,"

Availability analysis of bleaching system of a paper plant", Journal of Industrial Engg, Vol. 32 No. 1, pp. 24-29.

[7] Khanduja, R., Tewari, P. C. and Kumar, D., 2012, "Steady state behaviour and maintenance planning of bleaching system in a paper plant", , International Journal of Industrial Engg, Vol. 7 No. 2, pp. 39-44.

[8] Kumar, S., Tewari, P. C. and Kumar, S., 2007, Performance Modelling and Simulated Availability of Shell Gasification and Carbon Recovery Unit of Urea Plant. Proceedings of the 16th IASTED International Conference held at Spain, 409413.

[9] Kumar, S., Kumar, D. and Mehta, N. P., 2000, Probabilistic analysis of desulphurization system in urea fertilizer plant. Journal of Institution of Engineers (India), 80, 135-139.

[10] Jindal, Shalini., Garg, Reena, Garg, Tarun, 2020, Analysis of the reliability of the Butter-oil Prrocessing plant using CAS Mathematica and Maxima, IJRTE(India), 8(6), 4966-4972.

[11] Kumar, S., Tewari, P. C. and Rajiv, S., 2007, Simulated availability of $\mathrm{CO} 2$ cooling system in a fertilizer plant. Industrial Engineering Journal (Indian Institution of Industrial Engineering, Mumbai), 36(10), 19-23.

[12] Lindemann C, Malhotra M, Trivedi KS. Numerical methods for reliability evaluation of markov closed fault-tolerant systems. IEEE Transactions on Reliability.1995; 44(4):694704. Crossref.

[13] Modgil, V., Sharma, S.K., and Singh, J. (2013), "Performance modelling and availability analysis of shoe upper manufacturing unit", International Journal of Quality and Reliability Management, Vol. 30 No. 8, pp. 816-831.

[14] Srinath, L. S., 1994, Reliability Engineering. 3rd edition, East-West Press Pvt. Ltd., New Delhi, India.

[15] Shooman, M. L., 1996, Reliability Computation for Systems with Dependents Failures. Proceedings of IEEE Annual Symposium on Reliability, 44-56.

[16] Garg S, Singh J, Singh DV., Mathematical modelling and performance analysis of combed yarn production system: Based on few data. Journal of Applied Mathematical Modelling. 2010; 34 (11):3300-08.

[17] Shakuntla S, Lal AK, Bhatia SS, Singh J. Reliability analysis of polytube industry using supplementary variable technique. Applied Mathematics and Computation. 2011; 218(8): 3981-92. Crossref.

[18] Cekyay B, Ozekici S. Reliability MTTF and steady-state availability analysis of systems with exponential lifetimes. Applied Mathematical Modelling. 2015; 39(1):284-96. Crossref.

[19] T Garg, Application of CAS Maxima to the Availability Analysis of Screening Unit in a paper plant, International Journal of Computer \& Mathematical Sciences, IJCMS ISSN 2347 - 8527 Vol 4, Issue 6, June 2015.

[20] Sandler, G.H. (1993), System Reliability Engineering, Printice-Hall, Englewood Cliffs, NJ.

[21] Srinath L.S.(1994), Reliability Engineering, 3rd edition, East-West Press Pvt. Ltd., India. 